\title{
Citizenship Concepts in LINC Classrooms
}

\section{Tracey M. Derwing and Ronald I. Thomson}

In this study we surveyed teachers and program coordinators of Language Instruction for Newcomers to Canada (LINC) from Ontario, British Columbia, and Alberta to determine to what degree they believe they are incorporating citizenship concepts into the ESL classroom. Respondents provided us with information on the nature of their programs, the role of LINC, the types of materials they used, general course content, challenges faced, and their evaluation of the success of LINC in view of the government mandate to provide instruction that will lead to social integration. Most LINC providers felt that their programs were well tailored to the needs of their students, but in general they did not see LINC as a substitute for citizenship preparation courses. We recommend that optional citizenship courses be made widely available to immigrants after LINC, where the focus is on complex issues facing Canadians rather than a superficial coverage of facts for the citizenship test.

Au cours de cette étude, nous avons fait un sondage auprès d'enseignants et de coordonnateurs du programme Cours de langue pour les immigrants au Canada (CLIC) en Ontario, en Colombie britannique et en Alberta, pour déterminer à quel point ils croyaient intégrer des concepts d'éducation civique dans leur salle de classe d'ALS. Les répondants nous ont fourni des renseignements sur la nature de leurs programmes, le rôle de CLIC, le genre de matériaux employés, le contenu général de leurs cours, les défis affrontés, ainsi que leur évaluation de la mesure dans laquelle le programme CLIC réussissait à respecter le mandat du gouvernement voulant que l'instruction mène à l'intégration sociale. Alors que la majorité des intervenants croyaient que leurs programmes étaient bien adaptés aux besoins de leurs étudiants, ils ne percevaient pas, de façon générale, que CLIC remplaçait les cours d'éducation civique. Nous recommandons que des cours facultatifs d'éducation civique soient offerts aux immigrants après le programme $C L I C$, et que ces cours portent principalement sur les questions complexes auxquelles font face les Canadiens, et non sur des faits superficiels devant servir à l'examen pour la citoyenneté.

Since 1992, with the inception of LINC, it has been the policy of the federal government of Canada that introductory ESL classes focus on language for integration. The federally funded language training program immediately prior to LINC (from 1965 to 1992) emphasized preparation for employment and little in terms of general Canadian social content. The intent of the LINC policy was for language teachers to promote the development of citizenship 
values (although these were never defined by the government). While recent articles have focused on describing what constitutes Canadian cultural values and how these should be taught (Fleming, 2003; James, 2000), little attention has been paid to teacher's views. In this study, we investigate to what extent LINC teachers believe that they include citizenship values in their course content and to what extent they feel it is their responsibility to do so.

The notion that citizenship concepts can be taught to adult immigrants in language classrooms has been around for a long time. The Education of the New Canadian (Anderson, 1918) and A Handbook for New Canadians (Fitzpatrick, 1919) were designed to encourage immigrants to conform to "Canadian" values. Both of these volumes cite characteristics associated with various ethnic groups, and comment on their suitability to Canada. Compare Anderson's (1918) views of the Scandinavians versus the Chinese:

(1) There is no finer type of foreign immigrant to Canada than the Scandinavians. They are a close second, indeed if not equal, to the British and American immigrants. The Scandinavians readily become assimilated to the new life of the Dominion; a very large proportion of them naturalize. They make frugal, industrious citizens, an asset to any young country. (p. 200)

(2) Gambling seems to be a besetting vice of Chinese, probably due to their social isolation. But on the whole, the Chinese are industrious, inoffensive and well behaved. Their industry would make them a splendid asset, but race antipathy has decreed that Canada shall never have a large influx from China. The head tax is large and serves also as a check on immigration. (p. 221)

The instructors for whom these books were intended were told that newcomers should be given "a necessary knowledge of English, and an insight into Canadian affairs, which will tend to make them efficient healthy, selfrespecting citizens" (Anderson, 1918). Fitzpatrick (1919) adds,

It may be argued that the task of assimilating so many diverse peoples is a slow one.... in the interest of the rising generation and those unborn, it is incumbent upon us that assimilative forces be carefully and expeditiously set to work. The children in the public schools of today will be the fathers and mothers of the next generation, and it is essential that the former be given an insight into our Canadian life and ideals, so that they in turn may impart these to their offspring. (p. 238)

Although the overtly assimilationist stance of the authors in the early 20th century is no longer the approach taken by instructors of adult immigrants, there are some common threads in that it is still believed that language is crucial to integration and that immigrants will benefit from understanding 
Canadian society. Just as public schools are entrusted with developing citizens (Sears \& Hughes, 1996), language classes for adult immigrants have historically been places where immigrants can learn about some of the customs and values of their new country, if not be shaped by those values.

Federally funded language instruction was first introduced in Canada in 1947; at that time the emphasis was still on the explicit assimilation of newcomers (Joshee, 1996). However, in 1965 the Department of Manpower and Immigration became responsible for the language training of immigrants who were planning to enter the labor force (Cleghorn, 2000). At that point, most federally sponsored programs were mandated to emphasize employment. These programs were aimed at the declared breadwinner in the household regardless of actual employment status; far more men than women were able to access ESL because men were more likely to be deemed the principal breadwinners. When the LINC program was first introduced in 1992, it brought a swing of the pendulum in the content focus of language training for new immigrants: integration into Canadian society became the object of the language training rather than a narrower concentration on employability: "Training will normally be offered during an immigrant's first year in Canada and will place greater emphasis on introducing newcomers to shared Canadian values, rights and responsibilities" (Government of Canada, 1991b, p. 3)

LINC was also intended to broaden the scope of language programming to include greater numbers of women and to ensure that more people who entered the country with limited or no skills in English would have language programming available to them. The federal government indicated that it would be willing to fund a variety of program models; it encouraged flexibility and programs that were especially designed to meet learners' needs:

Different forms of training responsive to client needs-full-time, parttime, classroom-based, workplace-based, or neighborhood-based training-will be identified locally ... Suppliers could include local school boards, provinces, voluntary groups, commercial training institutes, and universities. Televised training, home study and other distance education models will also be explored. (Government of Canada, 1991b, p.

5)

This change in direction gave rise to several new providers, in addition to the traditional institutional deliverers of ESL programs. Some have argued that the result of opening LINC to commercial enterprises was not so much a way to enhance flexible and innovative programming as a watering down of both the quality of programs and the professionalism of the field (Cleghorn, 2000; Sauvé, 1996) motivated by a desire to save money. In many instances LINC teachers in the new programs were paid far less than those in institutions that had previously provided ESL and had considerably less or no 
professional preparation. Several new enterprises opened their doors and started delivering federally funded classes despite the lack of qualified instructors.

\section{Citizenship Content and LINC}

Another striking ramification of LINC was the need to develop curricula that encompassed Canadian culture. In a census of ESL and English language citizenship programs in Canada, Derwing and Munro (1987) found that before the introduction of LINC, only a small minority of ESL programs placed any significant emphasis on Canadian content of any kind, much less citizenship concepts.

When LINC was first implemented, the federal government distributed a manual entitled Canada: A Source Book for Orientation, Language and Settlement workers (Government of Canada, 1991a) as a basis for curriculum. Presumably the content was intended to reflect the "values, rights and responsibilities" that LINC was supposed to promote. The book identified "core concepts," which included behavioral guidelines, rights, facts, and generalizations about values. For example, the resource indicated that "Canadian conventions of personal hygiene and modesty are at the conservative end of the western international spectrum" (p. 105). In that section, immigrants were given the imperative "Do not defecate or urinate anywhere other than a private or public toilet" (p. 107) among other things. Charter rights such as the right to freedom of belief and religious expression were also included, as well as facts regarding political boundaries ("Canada is a federation of ten provinces ...") and sweeping statements such as "Canadians respect authority, but they demand justification for its actions" (p. 267). As Fleming (2003) and Thomson and Derwing (2004) have pointed out, this resource was widely criticized by settlement agencies, ethnic organizations, ESL providers, and the national media both for its condescending attitude toward new immigrants and for its oversimplification of content. The Source Book was quickly withdrawn.

The realization that good pedagogical materials were needed coincided with publishers' interest in producing new Canadian ESL titles. The early 1990s saw the release of more Canadian-authored ESL textbooks than ever before, although the representation of Canadiana in most such commercial textbooks is lacking in substance (Fleming, 2003; Ilieva, 2000; Thomson \& Derwing, 2004) and what content is Canadian tends to be stereotypical in nature.

Given the mandate of LINC, determining which aspects of Canadian culture to present and how they should be presented also became matters of concern. Just how does one define Canadian culture, Canadian values, and what it means to be a Canadian citizen? Are citizenship concepts and culture one and the same? After the public relations disaster concerning the Source 
Book, the federal government left the responsibility of determining what constituted citizenship values to LINC providers. Courchêne (1996) advocated an approach that would include historical information about how the country was shaped; including "common rights and freedoms" (p. 7) as expressed in the Constitution and the Charter of Rights, an exploration of the inequities within Canadian society, and common traditions and symbols of Canada. He suggested that to introduce this content satisfactorily into the classroom, several factors must be considered, including teacher preparation, pedagogical activities, and ways of achieving a balance of traditional and new beliefs from a variety of cultures.

Sauvé (1996), in a response to Courchêne, asserted that there are a number of limitations associated with taking a content-based approach to teaching Canadian culture in the ESL classroom, not the least of which is identifying what is and what is not Canadian. Her argument was two-pronged: first, she indicated that some aspects of culture are not consciously overt and therefore cannot be taught, and second, she maintained that culture is dictated by context and therefore difficult to teach as classroom content divorced from real world experience. Indeed, she claimed, "Culture is not about content. It is about the making and remaking of relationships in our society" (p. 23). Sauvé advocated having students make observations of the behavior of Canadians; these observations could then serve as the basis of class discussions. Ilieva (2001) has taken the notion of having students observe behavior much further. She advocates cultural exploration in which ESL students are given ethnographic tools. In addition to systematically observing both the behavior of their interlocutors and themselves, the students engage in classroom discussions that are guided by questions from the instructor. Specific pedagogical techniques to develop the type of cross-cultural awareness suggested by Ilieva have been described in Murray and Bollinger (2001).

Fleming (2003) extends the notion of immigrant language learning as the co-construction of identity for newcomers and Canadians. He argues that assumptions that a Canadian culture can be defined should be replaced with a realization that as globalization intensifies, so should the acceptance of a new sort of culture: one that is more fluid, diverse, and defined not in terms of prescribed norms, but as a national identity that is the sum of the personal identities that comprise it.

One way to gauge the success of LINC programs in fostering citizenship concepts is to ask former students how helpful their LINC classes were. Hart and Cumming (1997) did just that. "Respondents were clear ... to observe that LINC only provided them with a basic facility in English and orientation to Canada" (p. 91). Although most of the students interviewed felt that they had benefited from LINC, some indicated that they would have preferred small and less diverse classes, more help with particular aspects of ESL, and more instruction on "aspects of Canadian society and its political systems" (p. 91, 
italics added). Interestingly, the participants in the study were all drawn from Ontario, a province where students can attend LINC to level 5, whereas in BC and Alberta at the time of Hart and Cumming's study, students could only attend to level 3. In James' (2000) assessment of the cultural content in the LINC curriculum in Ontario, he concluded that it did not provide adequate emphasis on the learners' own cultural background. Furthermore, he found that none of the cultural items in the LINC curriculum in Ontario mentioned values or beliefs. Rather, most were focused on superficial cultural differences. It is safe to assume that adult LINC students in the western provinces would have had even less support, not only in terms of ESL, but also in terms of exposure to citizenship concepts by virtue of the limits put on instruction time and the lower linguistic proficiency of the students.

\section{Citizenship Courses}

One could argue that citizenship concepts are better presented in citizenship programs for adult immigrants than in ESL classes. Such programs can be taken once immigrants have been in the country for at least three years (when many immigrants have had more exposure to an official language and presumably higher proficiency). However, with the advent of LINC, and its mandate to incorporate values, rights, and responsibilities into the language curriculum, in addition to concomitant changes to the citizenship process, there has been a general decline in the quality and number of citizenship programs in Canada (Derwing, Jamieson, \& Munro, 1998). The transition from a hearing with a citizenship judge to a multiple-choice test and the elimination of the Citizenship Instruction and Language Training (CILT) agreement, which provided financial support for many citizenship programs, have resulted in far fewer citizenship education programs nationally. Those that remain tend to be shorter in length than they used to be and cover limited content. Derwing et al. (1998) maintain that the notion of citizenship education for adult immigrants has been trivialized to a small set of memorized facts-indeed, study sheets now appear in the yellow pages of some ethnic telephone directories, and they are certainly sufficient to get students through the citizenship exam.

Joshee and Derwing (in press) have shown that federal government officials believe that the ESL community is "doing citizenship education" in LINC. The current study was undertaken to determine to what extent teachers in LINC programs believe that they are able to introduce citizenship concepts into ESL classrooms. We did not define citizenship concepts, but asked instructors and administrators to respond to questions about the resources they use, the Canadian content in their classes, how they deal with cultural diversity issues in their programs, to what extent they address Canadian cultural values (both those on which there is relatively general 
agreement such as freedom of movement and those that are contentious such as abortion), and finally, what challenges they face.

\section{Method}

The questionnaire used here was adapted from a similar study in Quebec (Vermette, Jacquet, \& McAndrew, 2000). The resulting version was tested and then fine-tuned in response to the reactions of a LINC teacher who participated in the pilot session. The portion of the questionnaire addressed in this article appears in the Appendix.

We contacted programs in Toronto and Vancouver, the largest Englishspeaking immigrant-receiving cities in Canada. We also identified programs in mid-sized cities in Ontario, in British Columbia, and in Alberta, using ESL directories from the three provinces. The participating programs were selected to ensure a full range of contexts, from large public institutions to small private providers. A representative of each program was contacted and asked whether a telephone interview could be arranged at a time convenient to the respondent. In most cases we mailed or faxed the interview protocol to the program representative before the interview to give him or her an opportunity to think about the questions. Some participants preferred to return written responses by mail, but most of the questionnaires were dealt with over the phone.

In total, 85 programs were contacted (59 in Ontario, 14 in BC, and 12 in Alberta) and of those, 44 (52\%) participated in the study (30 in Ontario, 6 in $\mathrm{BC}$, and 8 in Alberta). There were multiple responses from some programs in BC (16 responses) and Alberta (12 responses). Roughly half the respondents were program directors or coordinators (although many of the directors reported that they also taught), and the rest were instructors. The interviews, conducted by one of two research assistants, took an average of 45 minutes to complete. Although most participants answered all the questions, there was some minor variability; the number of programs represented for each question ranges between 38 and 44 .

\section{Results}

\section{Profiles of Organizations Contacted}

At the time the study was conducted, BC and Alberta LINC programs offered language courses up to and including LINC level 3, whereas $56 \%$ of the programs in Ontario offered up to level 5. (Since then the policy in Alberta has changed, and programs are now allowed to offer level 4; the introductory language program in BC is called ELSA-English Language Services for Adults.) Fifty-nine percent of responding programs indicated that they offered only full-time courses (five hours or more per day); $24 \%$ offered only part-time; and $17 \%$ provided both full- and part-time courses. 
When asked whether LINC classes were designed for a specific group of students, most participants responded in the negative. Any targetting was mostly restricted to classes for women (12\%) and seniors (7\%). All programs indicated that the majority of their students had been in Canada for less than two years; $81 \%$ of the programs said that fewer than $10 \%$ of their learners had been in Canada for three years or more. Roughly a third (38\%) of the programs reported that between $10 \%$ and $20 \%$ of their students held jobs, whereas only $5 \%$ of students in another third of the responding programs were employed.

\section{Role of LINC}

When asked to define the role of LINC, most respondents said that it has dual responsibilities: to help newcomers integrate into Canadian society and to foster good language skills. Several participants from Alberta and BC mentioned "survival" English, in contrast to the teachers from Ontario. LINC programs were perceived to differ from other ESL programs primarily in that they are fully funded by the federal government.

\section{LINC Classroom Content}

Materials. Respondents were also asked what resources were used in their programs to teach Canadian values and laws. The most frequently cited materials were the daily newspaper $(90 \%)$, commercially produced textbooks $(87 \%)$, Citizen and Immigration publications $(83 \%)$, and printed handouts $(83 \%)$. When we examined the commercial materials, however, we found that although several texts were nominally Canadian, they were in fact of a United States nature and had little or no substantive Canadian-specific content (Thomson \& Derwing, 2004).

During the telephone interviews, respondents were also asked to identify gaps in the material. Several topics were suggested by the respondents as difficult to teach because suitable materials were unavailable. The current political situation, specific themes such as banking, Canadian materials, and Canadian content were all listed by the teachers as areas where they needed more resources. Moreover, the need for current information at an appropriate literacy level was mentioned by several respondents. Some participants felt that teachers were capable of filling the gaps by collecting material from a variety of sources. Thirty-nine percent of respondents indicated that there were no gaps, but as one respondent put it, "while materials are numerous, they are also widely scattered and require time to collect and organize."

Course content. With regard to course content, respondents were asked to rate the degree to which several topics related to citizenship were covered in their classes on a 5 -point Likert scale $(1=$ not at all, $5=$ very frequently). Culture and geography were the most extensively covered topics, with mean ratings of 4.5 and 4.0 respectively. History and democracy were next; the 
mean score of both was 3.2. The least covered topic was the economy, with a mean score of 2.9.

Generally, class discussions were cited as the most common method of introducing citizenship concepts. Respondents also mentioned having the students engage in cultural comparisons and research projects. Frequently respondents indicated that they use an emerging curriculum approach; that is, they cover topics as they come up in discussion or as they evolve in current events. Similarly, abstract concepts such as democracy and capitalism tended to be dealt with only on a need-to-know basis, usually when students brought up the topics themselves. In total, $96 \%$ of the respondents reported that they utilize real-life examples to introduce citizenship issues, particularly through field trips. Popular destinations were citizenship ceremonies, the police station, and city hall.

Essentially, all participants indicated that it was necessary to incorporate cultural diversity into the curriculum. Generally, instructors reported that they encourage students to compare their cultures with Canadian culture and with those of the other learners. This is accomplished through techniques such as oral presentations, role-plays, class discussion, and the celebration of cultural holidays. One respondent stated, "Diversity is evident in the classroom. Therefore, we utilize the diversity to develop a shared understanding of the world; learning English through meaningful education." Another respondent stated "tolerance and mutual self-respect is fundamental, because my students are from around the world." Furthermore, nearly all the programs included discussions on the contributions of various cultures to the development of Canadian society.

All the participants agreed that teaching Canadian cultural values was important to them personally. Although there was a wide variety of responses, it was the general consensus that knowledge of cultural values aids integration into Canadian society. Abstract values such as multiculturalism were discussed, but most participants focused on concrete aspects of the culture such as what to do if your neighbor's father dies, or when it is appropriate to shake someone's hand. As one participant stated, "I focus more on typical cultural behavior rather than on values."

Participants were asked specifically about their coverage of non-consensual and consensual values. By consensual we meant issues about which there is more or less general agreement in Canadian society, for example, freedom of movement (although recent Citizenship and Immigration discussions regarding settlement in small centers raised debate over this point). Nonconsensual issues are those around which there is a great deal of controversy, for example, abortion. As in the discussion of citizenship issues and Canadian values, participants felt that these topics needed to be approached carefully. As one instructor said, "Some [topics] are potential mine fields if the teachers don't take into account the make-up of the class and the in- 
dividuals in them." Another problem cited was language proficiency. When participants were asked how they taught the difference between consensual and nonconsensual values, one participant from Alberta said, "We usually can't. The language barriers are usually too great to try without interpretation [i.e., interpreters] and that is difficult." Several participants suggested that cultural issues must be dealt with carefully. For example, one respondent said, "We have to approach these issues slowly; start with simple things. Some students are not ready to listen."

\section{Preparation for the Citizenship Test}

Only a small minority of participants in Alberta (22\%) and BC (25\%) felt that the LINC classes prepare students for the citizenship test. In contrast, $48 \%$ of respondents in Ontario felt that LINC provides good preparation for the test. However, most participants were positive in their evaluation of LINC's role in preparing students to become full citizens. Sixty percent felt that LINC prepares students to participate in their new society. One respondent from Ontario phrased it this way: "We have never considered it our role as LINC teachers to prepare students for the citizenship exam, but we do feel it is part of the program to develop attitudes, skills, and knowledge that are essentially Canadian." Ninety-three percent of the respondents reported that their students find citizenship concepts interesting. As one individual said, "[Students] want to know about Canada. They want to know about the environment, so that they can establish themselves and become Canadian citizens."

\section{Challenges}

Participants were also asked to discuss specific difficulties that they experienced when teaching LINC classes. One weakness identified in the interviews was the lack of a set curriculum. Continuous intake was also considered a drawback, making it "hard to teach and make lesson plans." With regard to citizenship issues, some respondents mentioned concrete concepts, some of which fall within the requirements of the exam (e.g., geography) and others that are more language-specific rather than related to citizenship (e.g., grammar). Other participants focused on abstract concepts (e.g., participation, tolerance). A lack of appropriate materials and knowledge were mentioned: "It's hard to keep up unless you have a personal interest." Furthermore, specific student characteristics such as attitudes and previous experience were identified as determining to what extent certain topics could be addressed. As one instructor said, "People bring a lot of emotional stuff into the classroom.... The cynicism of the students can be hard to counteract. 'You only get a job if you know someone' is a typical student statement." In Alberta and BC the issues of limited language proficiency and time limitations were also mentioned: "There is not remotely 
enough time to develop language competence to a level where citizenship can become a topic."

\section{Evaluation of LINC}

All the respondents were positive about the LINC program. Although they viewed LINC as essential and worthwhile, several of the participants felt that its value was dependent largely on the ability of the instructor. "I think that the success of the program is based less on how well the curriculum has been prepared than on how good the teachers are." The sentiment in this statement was expressed by many program coordinators and instructors.

\section{Discussion}

\section{Profiles of Organizations}

It is clear from the responses that the goal of the federal government to encourage newcomers to take LINC in their first year in Canada is by and large being met. A sizeable majority of immigrants access LINC training on arrival long before they are eligible for citizenship (after three years). This fact may have implications for students in that their motivation to learn about Canadian values may be overshadowed by more pressing concerns for the development of general linguistic proficiency and employment opportunities.

Most of the students attend full time in culturally diverse classrooms where they are immediately faced with the heterogeneous Canadian reality. There are obvious disparities, however, in accessibility. The fact that a nationally administered and funded program has differential levels of support across provincial boundaries is clearly unfair. How much a student can acquire, both in terms of language skills and background knowledge, is partly determined by how long he or she is allowed to study. The discrepancies across provinces were evident in many of the questions asked where it was clear that teachers in Ontario with funding for LINC 5 could lead deeper discussions with their students with a more critical focus simply because the language proficiency of their students was higher than that of students in provinces where LINC is available only to levels 3 or 4 .

\section{Role of LINC}

Teachers accepted the dual role of LINC as defined by the federal government to develop language skills and to help newcomers integrate into society, despite the absence of a definition of integration or material to support their work. However, as mentioned above, the inequities in access to higher LINC levels across provinces clearly limited the extent to which more abstract concepts could be discussed in class. 


\section{LINC Classroom Content}

Materials. The materials available to teachers varied, but there was general agreement that it was difficult for them to address topical issues without extensive lesson preparation. Most of the commonly used textbooks do not incorporate significant Canadian content (Thomson \& Derwing, 2004), and for current affairs teachers are almost entirely reliant on newspapers or TV. The language of the media would be difficult for many LINC learners to understand without considerable adaptation, a time-consuming task for teachers. To make matters even more difficult, instructors' own educational backgrounds often do not include aspects of Canadian law, history, the economy, and other relatively factual topics, much less cultural values. Although many respondents indicated that they thought it was important to deal with issues such as racial and gender equity, multiculturalism, and the like, they tended to rely on teaching concrete conventions that arose from their own personal experiences. This is an understandable response on their part, given that much of what they cover comes up unexpectedly and given the limited language skills of the students. The shortcomings of this approach have been dealt with elsewhere (Sauvé, 1996; Ilieva, 2001; Fleming, 2003), but the fault lies not with the teachers, but with unrealistic expectations on the part of the federal government.

Course content. In general, citizenship-related topics (e.g., geography, history, politics) were introduced in some form in the LINC programs surveyed in spite of shortcomings in the published materials available. Although teaching factual aspects of culture can be important and provides students with valuable general knowledge, if culture instruction is limited to this, teachers run the risk of conveying to students a decontextualized view of culture, which can often result in the development of stereotypes.

The teachers indicated that cultural values were sometimes discussed; however, the most commonly cited approach employed was a form of contrastive analysis whereby phenomena from the learners' cultures were compared with related phenomena in the target culture. This approach can oversimplify the richness of culture and may lead to what Guest (2002) refers to as cultural caricatures rather than cultural understanding. Dealing with cultural differences on this level is not conducive to the process of language socialization because it can result in the flattening of cultural particularities into a homogeneous stereotype (Duff \& Uchida, 1997).

The lack of direction for teachers about which core aspects of Canadian culture and values should be addressed is further evidenced by those who reported teaching citizenship concepts as they arise or on a need-to-know basis, in reaction to students' questions. Although it is clearly good pedagogy to respond to issues as they come up, it is unlikely that students' questions will provide a comprehensive focus on matters that will become important to them in order to participate fully in Canadian society. 
The lack of curricular support for teachers in LINC programs in Ontario was demonstrated by James (2000), who evaluated the LINC curriculum on the basis of core aspects of cultural instruction. He argued that balanced exposure to and promotion of Canadian cultural values, as well as those of the learners' own cultures, and the development of cross-cultural awareness and empowering tools for learners' successful participation in the target culture should be major components. He found the curriculum very weak in these respects.

Course content is affected not only by curriculum or lack of it, but also by the linguistic proficiency of the students. Not only does discussing controversial nonconsensual topics require higher proficiency on the part of the students, but such topics can easily lead to misunderstandings and tensions even in the context of a conversation between native speakers. When such issues are addressed, there is a possibility that learners will experience feelings of alienation or even conflict that cannot be easily resolved when language skills are limited.

\section{Preparation for the Citizenship Test}

Again, the proficiency level of the students was a central issue in the ability of LINC teachers to offer support for the citizenship test. Participants from Ontario, where LINC is offered to level 5, were most likely to indicate that LINC provides such preparation, but even in that province only $48 \%$ of teachers held this view. In the other provinces, where LINC is limited to levels 3 or 4 , the respondents were far less inclined to see their classes as providing the necessary background knowledge for the citizenship test.

Apart from limitations imposed by the students' proficiency level, the content in language classes is limited by time. LINC teachers are obliged to provide students with language content other than the highly circumscribed topics that are the basis of the citizenship test.

\section{Challenges}

When respondents were asked to elaborate on general challenges that arise in fulfilling LINC's mandate, common themes emerged: the inadequacy of materials, insufficient teacher preparation, and the low linguistic proficiency of the students.

\section{Evaluation of LINC}

Teachers and programmers are generally happy with LINC. From their perspective, they are offering what the government intended (although James, 2000, has argued that what the government intended is not reflected in LINC Ontario curriculum guidelines). In fact teachers have opted for a pragmatic solution to the problem of being asked to provide their students with the skills to integrate into Canadian society through the inculcation of values. They have defined their own responsibilities as being first and 
foremost the instruction of language, focusing as much as possible on survival language and concrete factual information.

The federal government, on the other hand, has come to the conclusion that LINC has not been entirely successful in meeting some of its goals; and indeed, it has begun to question the goals themselves. In 2004 they introduced the Enhanced Language Training initiative: \$20 million annually will go toward providing higher levels of language training specifically geared to ensuring that adult immigrants enter and remain in the labor market at levels that will make full use of their skills and credentials (Citizenship and Immigration Canada, 2004). The supposition that graduates from LINC programs would have sufficient language skills to further develop linguistically on their own clearly has not been supported.

\section{Recommendations}

There needs to be Canadian content in LINC, but what we believe students need is instruction that is timely: language competence and access to information that will be of immediate use to them such as health care, car insurance, city bylaws, day-to-day survival skills, and issues related to employment. Newcomers are dealing with adjustment issues at the same time as they are studying English, and the content most useful to them is information that will help them with that adjustment.

Because the failure of LINC to provide explicit content-based citizenship instruction is largely due to linguistic proficiency level and the lack of immediate relevance to students who are recently arrived, it is perhaps time to reconsider whether such citizenship instruction is appropriate, and if so, in what context. Perhaps the most important component of citizenship preparation is language itself. It is unrealistic to believe that at the low proficiency levels afforded by LINC new immigrants will gain the language skills necessary to participate fully in their new society. Of course, language proficiency does not guarantee participation; neither does it guarantee "good citizenship." However, language ability does provide the foundation necessary for constructing a Canadian identity through growing participation in the wider community. Wringe (1996) points out that language provides access to specific cultural, administrative, and service institutions; it allows individuals the capacity to scrutinize governmental activities and to participate in the democratic process, which is in large part what it means to be a citizen in a liberal democracy. "Not to speak the language of those around one is to be less than equal, dependent on others, one may be included or excluded at will" (p. 74). Immigrants from larger ethnic communities in Canada may be able to access critical information through multilingual media. However, total reliance on such sources limits their interaction with the broader community. 
Paradoxically, the successful development of second-language proficiency necessary to gain equality is heavily dependent on the learners' ability to engage in the target society. Proponents of identity theory in SLA such as Norton and Toohey (2001) argue that the power relationship that exists between native speakers and non-native speakers often precludes learners' interaction with native speakers. Consequently, if newcomers are to become active citizens, perhaps the language classroom should provide a greater emphasis on tools necessary to overcome limitations imposed by this power relationship.

One approach to such citizenship instruction might be to provide students with strategies for accessing contexts where exposure to the language of citizenship is most naturally obtained (Thomson \& Derwing, 2004; Ilieva, 2001; Fleming, 2003). Rather than simply teaching discrete facts about Canadian history, geography, and law, prospective citizens should be provided with the language needed to participate fully in a multicultural liberal democracy. As learners begin to understand their freedoms as individuals, they are more likely to overcome what Guest (2002) suggests is a hypersensitivity to perceived differences. Early in the immigrants' experience, perceptions of difference based on a contrastive approach may have a paralyzing effect on the their willingness and ability to participate in Canadian society. As they begin to recognize the dynamic nature of culture characterized by acceptance of difference, their fear of risk-taking may diminish. Guest (2002) suggests that students should be made aware that cultures, including their own, are not monoliths. National cultures have many subcultures. Developing an ability to navigate a multiplicity of subcultures should be the essence of cultural instruction.

The choice of propositional content in terms of history, politics, and the like should be motivated by the underlying values and world view the teacher wishes to portray. Rather than teaching discrete historical facts, these could be explored with students in such a way as to convey the underlying reason for their importance. Holden (1996) argues for the teaching of history through a human rights perspective. This requires linkages to be drawn between historical events and their implications in terms of human rights (e.g., Tommy Douglas's approach to universal health care). It is a tall order for LINC teachers to introduce Canadian values as the policymakers intended, and one that cannot be met. The teachers in this survey have taken a very pragmatic approach to their directives and in so doing have probably struck a balance between survival English and informative "facts" that probably satisfies the students' most immediate needs better than a focus on values ever could given the context.

If formal citizenship education is to exist at all, we argue that it should consist of optional courses made available to people who wish to learn more about becoming a citizen once they have been in the country for about three 
years. Such courses would include the factual information required on the test, but far more important would be discussions of competing values, current issues facing Canadians, and a deeper understanding of how Canada came to be the country it is today. The classes should be taught by ESL professionals who can incorporate additional language learning opportunities into what would be essentially a course that leads to a broad view of the many subcultures in Canadian society.

At the beginning of this article we criticize the stance taken by citizenship/ESL educators from the early 20th century. However, at the same time that Anderson and Fitzpatrick argued for the implementation of assimilative forces, others held a view much more in keeping with our own understanding of citizenship. John Ralston Saul (1997) cites a 1913 citizenship class in which the Duties of a Citizen were outlined as follows: Understand our Government; Take active part in politics; Assist all good causes; Lessen intemperance; Work for others (p. 130).

We believe that many language teachers demonstrate the latter values in their own dealings with their students, but that LINC in its current form cannot provide students with sufficient access to the linguistic skills and cultural knowledge they need to ensure full citizenship. In an interview at a citizenship test, when asked why he chose to become a Canadian citizen, an immigrant said, "Because I want to be grateful to this country, joining my efforts to build a better and united Canada. A Canada that opens to me a new dimension of co-existence." Another said, "I live here; I want to spend my life here. I want to be a full member of the Canadian community." These goals point to the need for discussions at a level of language proficiency that is commensurate with complex notions of belonging, a level that most LINC graduates have not attained.

\section{Acknowledgments}

The authors thank Marie McAndrew for generously providing us with the survey used in a study of citizenship concepts in French language programs for adult immigrants in Québec. Thanks also to Kama Jamieson and Marilyn Abbott, who assisted with the project. Georgia Ramos, Ron Smyth, Reva Joshee, and Marian Rossiter also offered help for which we are very grateful. Finally, we thank the Prairie Centre of Excellence for Research on Immigration and Integration, the Metropolis Project, and SSHRC for funding the project.

\section{The Authors}

Tracey Derwing is a professor of TESL in the Department of Educational Psychology at the University of Alberta. She is also Co-Director of the Prairie Centre of Excellence for Research on Immigration and Integration.

Ron Thomson is a doctoral student in linguistics at the University of Alberta; he completed an MEd in TESL at the same university. 


\section{References}

Anderson, J.T.M. (1918). The education of the new Canadian: A treatise on Canada's greatest educational problem. London and Toronto: J.M. Dent \& Sons.

Citizenship and Immigration Canada. (2004). Enhanced language training helps immigrants use their skills and credentials. Retrieved August 30, 2004, from: http:/ / www.news.gc.ca/cfmx/CCP/view/en/index.cfm?articleid=84729

Cleghorn, L. (2000). Valuing English: An ethnography of a federal language training program for adult immigrants. Unpublished master's thesis, Ontario Institute for Studies in Education of the University of Toronto.

Courchêne, R. (1996). Teaching Canadian culture: Teacher preparation. TESL Canada Journal, 13(2), 1-16.

Derwing, T.M., \& Munro, M.J. (1987). Citizenship instruction for adult ESL learners: An assessment of programs and services. Ottawa: Department of the Secretary of State.

Derwing, T.M., Jamieson, K., \& Munro, M.J. (1998). Citizenship education for adult immigrants: Changes over the last ten years. Alberta Journal of Educational Research, 44, 383-396.

Duff, P., \& Uchida, Y. (1997). The negotiation of teachers' sociocultural identities and practices in postsecondary EFL classrooms. TESOL Quarterly, 31, 451-486.

Fitzpatrick, A. (1919). Handbook for new Canadians. Toronto, ON: Ryerson Press.

Fleming, D. (2003). Building personal and nation-state identities: Research and practice. TESL Canada Journal, 20(2), 65-79.

Govrnment of Canada. (1991a). Canada: A source book for orientation, language and settlement workers. Ottawa: Employment and Immigration Canada.

Government of Canada. (1991b). Canada: A source book for orientation, language and settlement workers. Ottawa: Employment and Immigration Canada.

Guest, M. (2002). A critical "check book" for culture teaching and learning. ELT Journal, 56, 154-161.

Hart, D., \& Cumming, A. (1997). A follow-up study of people in Ontario completing level 3 of the Language Instruction for Newcomers to Canada (LINC) program. Report of the Ontario Region LINC Advisory Committee. Toronto, ON: Modern Language Centre, Ontario Institute for Studies in Education of the University of Toronto.

Holden, C. (1996). Enhancing history teaching through a human rights perspective. Evaluation and Research in Education, 10, 113-127.

Ilieva, R. (2000). Exploring culture in texts designed for use in adult ESL classrooms. TESL Canada Journal, 17(2), 50-63.

Ilieva, R. (2001). Living with ambiguity: Toward culture exploration in adult second-language classrooms. TESL Canada Journal, 19(1), 1-16.

James, M. (2000). Culture in ESL Instruction: An analytic framework. TESL Canada Journal, 17(2), 36-49.

Joshee, R. (1996). The federal government and citizenship education for newcomers. Canadian and International Education, 25, 108-127.

Joshee, R., \& Derwing, T.M. (in press). The unmaking of citizenship education for adult immigrants to Canada. Journal of International Migration and Integration.

Murray, G.L., \& Bollinger, D.J. (2001). Developing cross-cultural awareness: Learning through the experiences of others. TESL Canada Journal, 19(1), 62-72.

Norton, B., \& Toohey, K. (2001). Changing perspectives on the good language learner. TESOL Quarterly, 35, 307-322.

Sauvé, V. (1996). Working with the cultures of Canada in the ESL classroom: A response to Robert Courchêne. TESL Canada Journal, 13(2), 17-23.

Sears, A.M., \& Hughes, A.S. (1996). Citizenship education and current educational reform. Canadian Journal of Education, 21, 123-142. 
Thomson, R.I., \& Derwing, T.M. (2004). Presenting Canadian values in LINC: The roles of textbooks and teachers. TESL Canada Journal, 22(2), 17-33.

Vermette, M., Jacquette, M., \& McAndrew, M. (2000). Education à la citoyenneté et adultes nouveaux arrivants: l'expérience québécoise. Montréal, QC: Immigration et Métropoles.

Wringe, C. (1996). The role of foreign language learning in education for European citizenship. Evaluation and Research in Education, 10(2), 68-78.

\section{Appendix}

\section{Profile of Organizations Contacted}

1. Which levels of LINC does your organization offer and for how many hours a day?

2. Do you offer LINC classes targeted to a specific group? (e.g., seniors, immigrant women).

3. What percentage of your students work while they are attending LINC classes?

4. What percentages of your students have been in Canada

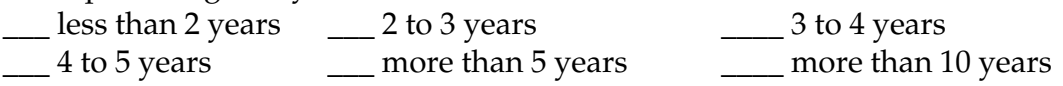

Role of LINC

5. We have the government's official description of LINC, but what we would like to know is what your organization sees the role of LINC to be.

6. How are LINC programs different from other ESL programs?

\section{LINC Classroom Content}

\section{Materials}

7. Please indicate which of the following citizenship instruction materials your instructors use in class and how often they use them. In this case we are referring to materials that are specifically designed to focus on Canadian values and laws.

$1=$ never, $2=$ seldom, $3=$ sometimes, $4=$ several times per course, $5=$ every class

- commercially produced textbooks

- printed handouts

- newspapers

- provincial publications

- Citizenship and Immigration publications

- printed handouts

- other (specify)

8. Which commercially produced textbooks are most frequently used in your LINC programs? (Both general texts and citizenship focussed texts)

9. Are there any gaps in materials available?

\section{Classroom content}

10. Rate the extent that you cover the following areas of citizenship on a 5 - point scale where $1=$ not at all and $5=$ very frequently.

_ geography economy history culture democracy 
11. What teaching strategies and activities do you use in the classroom to introduce this material?

12. How do you treat abstract concepts such as democracy, capitalism, etc?

13. How do you introduce cultural issues into the classroom? Can you give examples of specific techniques?

14. Do you utilize real life to introduce citizenship issues (e.g., field trips)?

15. How is cultural diversity treated in the curriculum?

16. Do you discuss the contribution of different cultures to the development of Canadian society in your classroom?

17. How do you take into consideration the different cultures represented in the class?

18. Do your students know about local cultural events?

19. Is the teaching of cultural values important to you as a teacher? Why (not)?

20. Is it important to provide learners with information about Canadian institutions and laws? How do you teach this?

21. How do you teach cultural values? Give examples of activities you use.

22. What are the most important cultural values to teach? Why?

23. Are discussions/debates of cultural norms in Canadian society useful (e.g., dating, child-rearing)?

24. Are discussions / debates of non-consensual values (the right to life, euthanasia, abortion, etc.) useful?

25. How do you teach the difference between consensual values (protected by law) and values subject to debate/non consensual?

\section{Challenges}

26. What aspects are the most difficult to teach regarding the required objectives of the program?

27. What aspects are the most difficult to teach regarding specific content or ideas?

28. What aspects are the most difficult to teach related to particular groups of people (ethnic origin, education level, L1, other).

29. What professional challenges do you face in introducing citizenship concepts into the LINC program?

30. Do the students find citizenship concepts interesting? How do you know?

31. With regard to promoting knowledge about Canada and Canadian values, what are the strengths and weaknesses of the program?

32. Is it possible to contribute to the socio-cultural development of learners?

33. Is the teaching of citizenship content evaluated? How?

\section{Preparation for the Citizenship Test}

34. Do you think the LINC program prepares students to pass the citizenship exam?

35. Generally do you think that this program prepares immigrants to become full citizens in their new society? Elaborate.

36. Do you have other suggestions/comments regarding citizenship education or related issues? 